\title{
Dissociable Control of Impulsivity in Rats by Dopamine D2/3 Receptors in the Core and Shell Subregions of the Nucleus Accumbens
}

\author{
Morgane Besson', David Belin', Ruth McNamara', David EH Theobald', Aude Castel', Victoria L Beckett', \\ Ben M Crittenden', Amy H Newman', Barry J Everitt', Trevor W Robbins' and Jeffrey W Dalley*,1,3 \\ 'Behavioral and Clinical Neuroscience Institute and Department of Experimental Psychology, University of Cambridge, Cambridge, UK; \\ ${ }^{2}$ Medicinal Chemistry Section, National Institute on Drug Abuse-IRP, National Institutes of Health, Baltimore, MD, USA; ${ }^{3}$ Department of \\ Psychiatry, University of Cambridge, Addenbrooke's Hospital, Cambridge, UK
}

Previous research has identified the nucleus accumbens (NAcb) as an important brain region underlying inter-individual variation in impulsive behavior. Such variation has been linked to decreased dopamine (DA) D2/3 receptor availability in the ventral striatum of rats exhibiting spontaneously high levels of impulsivity on a 5-choice serial reaction time (5-CSRT) test of sustained visual attention. This study investigated the involvement of DA D2/3 receptors in the NAcb core (NAcbC) and the NAcb shell (NAcbS) in impulsivity. We investigated the effects of a DA D2/3 receptor antagonist (nafadotride) and a DA D2/3 partial agonist (aripiprazole) infused directly into either the NAcbC or NAcbS of rats selected for high $(\mathrm{HI})$ and low $(\mathrm{LI})$ impulsivity on the 5-CSRT task. Nafadotride increased significantly the level of impulsivity when infused into the NAcbS, but decreased impulsivity when infused into the NAcbC of HI rats. By contrast, intraNAcb microinfusions of aripiprazole did not affect impulsivity. Systemic administration of nafadotride had no effect on impulsive behavior but increased the number of omissions and correct response latencies, whereas systemic injections of aripiprazole decreased impulsive and perseverative behavior, and increased the number of omissions and correct response latencies. These findings indicate an opponent modulation of impulsive behavior by DA D2/3 receptors in the NAcbS and NAcbC. Such divergent roles may have relevance for the etiology and treatment of clinical disorders of behavioral control, including attention-deficit hyperactivity disorder and drug addiction. Neuropsychopharmacology (2010) 35, 560-569; doi:I0.1038/npp.2009.162; published online 21 October 2009

Keywords: impulsivity; 5-CSRT task; NAcbs; DA receptors; nafadotride; aripiprazole

\section{INTRODUCTION}

Impulsivity is a multidimensional behavioral construct involving rash or risky behavior and a strong tendency toward spur-of-the-moment, poorly judged decisions and actions. Although it can be a beneficial personality trait, pathological manifestations of impulsivity are associated with a number of psychiatric disorders, including attentiondeficit hyperactivity disorder (ADHD) (Winstanley et al, 2006) and substance use disorders (Brewer and Potenza, 2008, DSMIV American Psychiatric Association).

Recent conceptualizations have categorized impulsivity in terms of deficiencies in decision-making, inhibitory response control (for example, stopping) and in bridging delays to future rewards (Winstanley et al, 2006; Dalley

*Correspondence: Dr JW Dalley, Department of Experimental Psychology, University of Cambridge, Downing Street, Cambridge, Cambridgeshire CB2 3EB, UK, Tel: +4401223765 29I,

Fax: + 4401223333 564, E-mail: jwd20@cam.ac.uk

Received 9 July 2009; revised 21 August 2009; accepted 2 September 2009 et al, 2007; Pattij and Vanderschuren, 2008; Eagle et al, 2008; Robinson et al, 2009). Although the neural substrates of impulsivity are only partly understood, considerable evidence points to a significant involvement of the nucleus accumbens (NAcbs) (Dalley et al, 2008; Pattij and Vanderschuren, 2008), a forebrain region involved in the integration and expression of motivated behavior (Mogenson et al, 1980; Robbins and Everitt, 1996). It has recently been suggested that NAcb dopamine (DA) mediates high impulsivity in rats, potentially through abnormal modulation of NAcb function by DA D2/3 receptors. Thus, rats exhibiting a trait-like form of impulsivity - characterized by an inability to withhold a response to a cued visual stimulus on a 5-choice serial reaction time (5-CSRT) task (Bari et al, 2008) - show a reduced density of DA D2/3 receptors in the ventral striatum as measured by positron emission tomography (Dalley et al, 2007). However, the precise anatomical locus of this reduction in DA D2/3 receptors in the NAcb is unclear and could involve changes in one or more subregions of the ventral striatum, including especially the NAcb core (NAcbC) and NAcb shell (NAcbS) (Groenewegen et al, 1999; Zahm, 1999, 2000). 

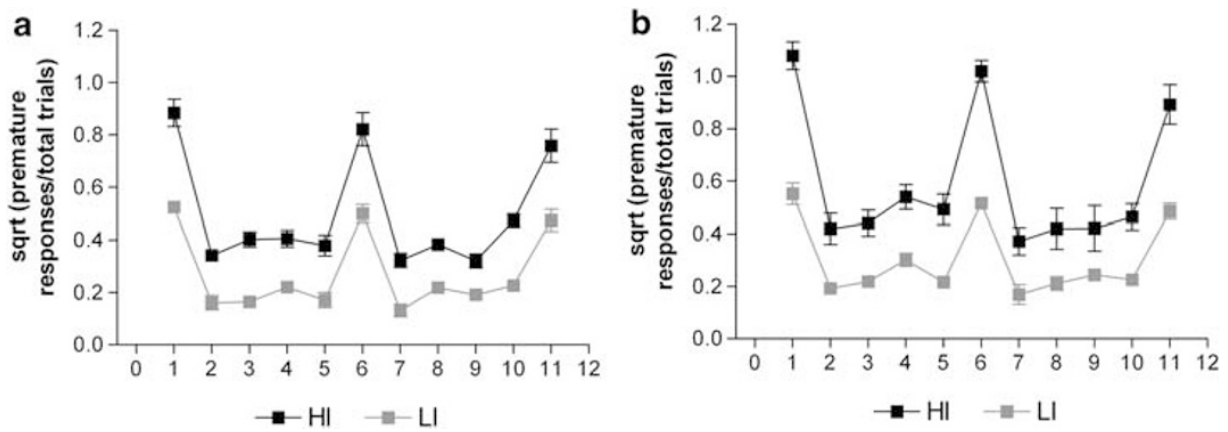

Figure I Levels of impulsivity expressed as square root of premature responses (premature responses/total trials) on the 5-CSRT task, during baseline

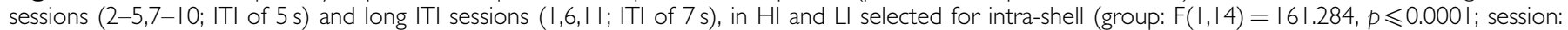
$F(|0| 40)=,64.58 I ; \quad p \leqslant 0.000 I$; group $\times$ session: $F(|0| 40)=2.440,, p \leqslant 0.00 I)$ (a) or intra-core (group: $F(I, \mid 4)=54.366, \quad p \leqslant 0.000 I$; session: $F(I 0, \mid$ I 40) $=54.658 ; p \leqslant 0.000 I$; group $\times$ session: $F(I 0, \mid 140)=5.203, p \leqslant 0.000 I)$ (b) microinfusion experiments.

In this study, we therefore sought to investigate the role of DA D2/3 receptors in the NAcbC and NAcbS in mediating inter-individual differences in impulsive behavior on the 5-CSRT task. The effects of intra-NAcbC vs intra-NAcbS infusions of the DA D2/3 receptor antagonist, nafadotride, (Sautel et al, 1995) and the DA D2/3 partial agonist, aripiprazole, (DeLeon et al, 2004) were investigated and compared with systemic administration of these drugs in rats previously selected for high (HI) or low (LI) impulsivity. On the basis of previous findings showing that intra-NAcbC infusions of DA D2/3 receptor antagonists generally reduce impulsive behavior on the 5-CSRT task (Pattij et al, 2007; Pezze et al, 2009), we predicted that, in HI animals, nafadotride would similarly reduce impulsive behavior following its administration into the NAcbC. As $\mathrm{HI}$ and LI rats are likely to display differences in DA activity (Pattij and Vanderschuren, 2008), we expected aripiprazole to exert differential effects between HI and LI animals, as it can display both agonist and antagonist actions depending on DA levels (Deleon et al, 2004). Furthermore, although the role of DA D2/3 receptors in the NAcbS has not previously been investigated in the context of 'trait-like' impulsivity, we hypothesized on the basis of previous research that DA $\mathrm{D} 2 / 3$ receptors in the $\mathrm{NAcbC}$ and NAcbS may make dissociable contributions to the regulatory control of impulsive behavior (Pattij et al, 2007; Murphy et al, 2008).

\section{MATERIALS AND METHODS}

\section{Subjects}

A total of 96 male Lister Hooded rats (Charles River, Kent, UK) were used, housed under humidity and temperaturecontrolled conditions and an alternating light/dark cycle (red lights on from 0730 to 1930 hours). Rats weighing $\sim 300 \mathrm{~g}$ at the start of the experiments were maintained at $85 \%$ of their free-feeding weight. Water was provided ad libitum. All experimental procedures were conducted in accordance to the UK Animals (Scientific procedures) Act 1986 (Home Office license number PPL 80/2234).

\section{5-CSRT Training}

Two groups of rats were trained in operant 5-CSRT task chambers $(25 \times 25 \times 25 \mathrm{~cm})$ controlled by WhiskerServer software (version 2.8) and FiveChoice client (version 2.6) (Cardinal and Aitken, 2001). Each daily session consisted of 100 discrete trials with stable performance being achieved after about 40 sessions. Animals were trained to enter a food magazine to initiate a trial. After an inter-trial-interval (ITI) of $5 \mathrm{~s}$ had elapsed, a brief light stimulus (0.5-s in duration) was pseudo-randomly presented in one of the five apertures. Following a nose poke in this aperture, (a 'correct' response) animals were rewarded with the delivery of one food pellet ( $45 \mathrm{mg}$ Noyes dustless pellets) in the magazine. A nose-poke response in any of the adjacent apertures (an 'incorrect response'), as well as a failure to respond within $5 \mathrm{~s}$ after the onset of the stimulus ('omission'), resulted in no food delivery and a time-out period with the house light extinguished for $5 \mathrm{~s}$. Nose pokes made during the ITI, that is, before the onset of the stimulus (or 'premature responses') were recorded as a measure of impulsivity, and resulted in a 5-s time-out and no food reward.

\section{Screening for HI and LI}

Following acquisition of the 5-CSRT task rats were challenged with three long ITI sessions to encourage impulsive responding, as described previously (Dalley et al, 2007; Belin et al, 2008; Economidou et al, 2009). Such sessions were presented at weekly intervals and consisted of a fixed long ITI of 7s. Subjects were ranked according to their level of impulsivity throughout the 3-week screening procedure and the highest and lowest 8 subjects selected as $\mathrm{HI}$ and LI rats, respectively. One group of $\mathrm{HI}$ and LI rats was selected for the intra-NAcbS infusions, which was subsequently also used for the systemic administration experiments (Figure 1a); another group of HI and LI animals was selected for the intra-NAcbC infusion experiment (Figure 1b).

\section{Surgery}

The HI and LI rats were anesthetized with ketamine (Ketaset, $100 \mathrm{mg} / \mathrm{kg}$, intraperitoneally (i.p.); Vet Drug, Bury St Edmunds, UK) and xylazine (Rompun, $10 \mathrm{mg} / \mathrm{kg}$, i.p., Vet Drug), and secured in a stereotaxic frame with the incisor bar set at $-3.3 \mathrm{~mm}$ relative to the interaural line in flat skull position. Bilateral 22-gauge double-guide cannulae (Plastics 
One, Sevenoaks, UK) were bilaterally implanted above either the NAcbC or the NAcbS, according to the following stereotaxic anterior-posterior (AP), mediolateral (ML), and dorsoventral (DV) coordinates: NAcbC: AP $+1.5 \mathrm{~mm}$, ML $\pm 1.9 \mathrm{~mm}, \mathrm{DV}-2.2 \mathrm{~mm}$; NAcbS: AP $+1.7 \mathrm{~mm}$, ML $\pm 0.75 \mathrm{~mm}, \mathrm{DV}-2 \mathrm{~mm}$. AP and ML coordinates were taken from bregma, DV coordinates from skull surface (Paxinos and Watson, 1998). Cannulae were secured to the skull with dental acrylic and stainless steel screws and occluded by a stylet. After surgery, animals were allowed to recover for a week.

\section{Microinfusions}

Following reestablishment of stable performance on the 5-CSRT task, intracerebral microinfusions of nafadotride and aripiprazole were carried out in HI and LI rats $5 \mathrm{~min}$ before behavioral testing. One rat from each group of $\mathrm{HI}$ animals was removed from the study because of unstable performance after surgery. The infusion experiments were run over a 3-day cycle, starting with an initial baseline session. On day 2, animals received an infusion of drug or vehicle ('veh') before testing. On day 3, animals were not tested and remained in their home cages. The microinfusions were delivered through a 28-gauge bilateral injector (Plastics One, Roanoke, USA) inserted through the guide cannula and extending $4.5 \mathrm{~mm}$ (NAcbC) or $5 \mathrm{~mm}$ (NAcbS) beyond the tip of the guide. The injector was left in place for $1 \mathrm{~min}$ before each $1 \mathrm{~min}$ infusion $(0.5 \mu \mathrm{l})$ and a further $1 \mathrm{~min}$ afterwards to allow sufficient time for the drug to diffuse into the surrounding tissue. Rats received two previous habituation sessions in the same testing conditions, separated by 2 days of baseline training. During the first habituation session, the injector was inserted through the guide cannula and left in place for $1 \mathrm{~min}$. During the second habituation session, rats received an infusion of vehicle. The first drug infusion was given after a further 2 days of baseline training. Rats first received infusions of nafadotride (veh, 0.1 and $0.3 \mu \mathrm{g}$ ) and aripiprazole (veh, $0.03,0.1$, and $0.3 \mu \mathrm{g}$ ) according to a randomized Latin-square design with a wash-out period of 1 week. The doses were selected according to previous research (Barik and de Beaurepaire, 2005) and pilot experiments. All drug testing was performed with sessions comprising a fixed ITI of $5 \mathrm{~s}$.

\section{Systemic Drug Administration}

Nafadotride and aripiprazole were administered by systemic intraperitoneal injection in $\mathrm{HI}$ and LI rats that had previously received intra-NAcbS microinfusions. Systemic injections were given 1 week after the last intracerebral infusion on a 3-day cycle as described above. Nafadotride and aripiprazole were injected $20 \mathrm{~min}$ before behavioral testing according to a Latin-square design (veh, 1 and $3 \mathrm{mg} /$ $\mathrm{kg}$ ) with a wash-out period of 1 week between both drugs. The doses were based on previously published research (Boulougouris et al, 2008; Nordquist et al, 2008; St Onge and Floresco, 2009). All drug testing was performed with sessions comprising a fixed ITI of $5 \mathrm{~s}$.

\section{Drugs}

Aripiprazole (Toronto Research Chemicals, North York, Canada) was dissolved in $2 \%$ glacial acetic acid and $30 \%$ dimethyl formamide in distilled deionized water. The $\mathrm{pH}$ was adjusted to 5.5 with $0.1 \mathrm{M} \mathrm{NaOH}$. Nafadotride (Tocris Cookson, Bristol, UK) was dissolved in $1 \mathrm{M} \mathrm{HCl}$ and normal saline and the $\mathrm{pH}$ adjusted to 6 with $0.1 \mathrm{M} \mathrm{NaOH}$. Both drugs were injected in a volume of $1 \mathrm{ml} / \mathrm{kg}$. All drugs were aliquoted after preparation and frozen at $-80^{\circ} \mathrm{C}$.

\section{Histological Assessment of Cannulae Placements}

Animals received an overdose of sodium pentobarbital ( $1.5 \mathrm{ml}$ per rat, i.p., Dolethal $200 \mathrm{mg} / \mathrm{ml}$, Rhone-Merieux, Athens, USA), and perfused transcardially with $0.01 \mathrm{M}$ PBS followed by $4 \%$ paraformaldehyde. The brains were removed and post-fixed in $4 \%$ paraformaldehyde overnight. The brains were transferred into a $20 \%$ sucrose solution in $0.01 \mathrm{M}$ PBS and left overnight before being sectioned into $60-\mu \mathrm{m}$ coronal sections with a freezing microtome. Every third section was mounted and stained with Cresyl Violet. Cannulae placements were verified under a light microscope and mapped onto standardized coronal sections of the rat brain (Paxinos and Watson, 1998).

\section{Statistical Analysis}

Two-way repeated-measures ANOVAs were used to analyze the effects of intra-NAcb microinfusions on 5-CSRT task performance in $\mathrm{HI}$ and LI rats (NAcb subregion $\times$ drug dose). For the analysis of the effects of intra-NAcb nafadotride, three-way repeated-measures ANOVAs were additionally performed (group $\times$ NAcb subregion $\times$ drug dose). The effects of systemic drugs administration were assessed by two-way repeated-measures ANOVA (groupdrug). If the sphericity assumption was violated, the Greenhouse-Geisser epsilon test was applied to calculate a more conservative $p$-value for each $\mathrm{F}$ ratio. On confirmation of significant main effects, differences among individual means were analyzed using the Duncan's post-hoc test. Significant violations of homogeneity of variances across the HI and the LI groups and of normality were corrected using square root transformations. For all analyses, the significance level was $\alpha=0.05$.

\section{RESULTS}

\section{Histology}

Figure 2 shows the positions of the injector tips in the NAcbC and NAcbS. In total, eight rats were excluded from the study (two HI and six LI) because injector cannulae were positioned outside the target areas. There was no gross tissue damage in the local vicinity of the injector tracks.

\section{Intra-NAcb Nafadotride Infusions}

The effects of intra-NAcb infusions of nafadotride on impulsive responding and other behavioral measures on the 5-CSRT task are shown in Figure 3 and Supplementary Table 1 (see Supplementary online material). In HI animals, 

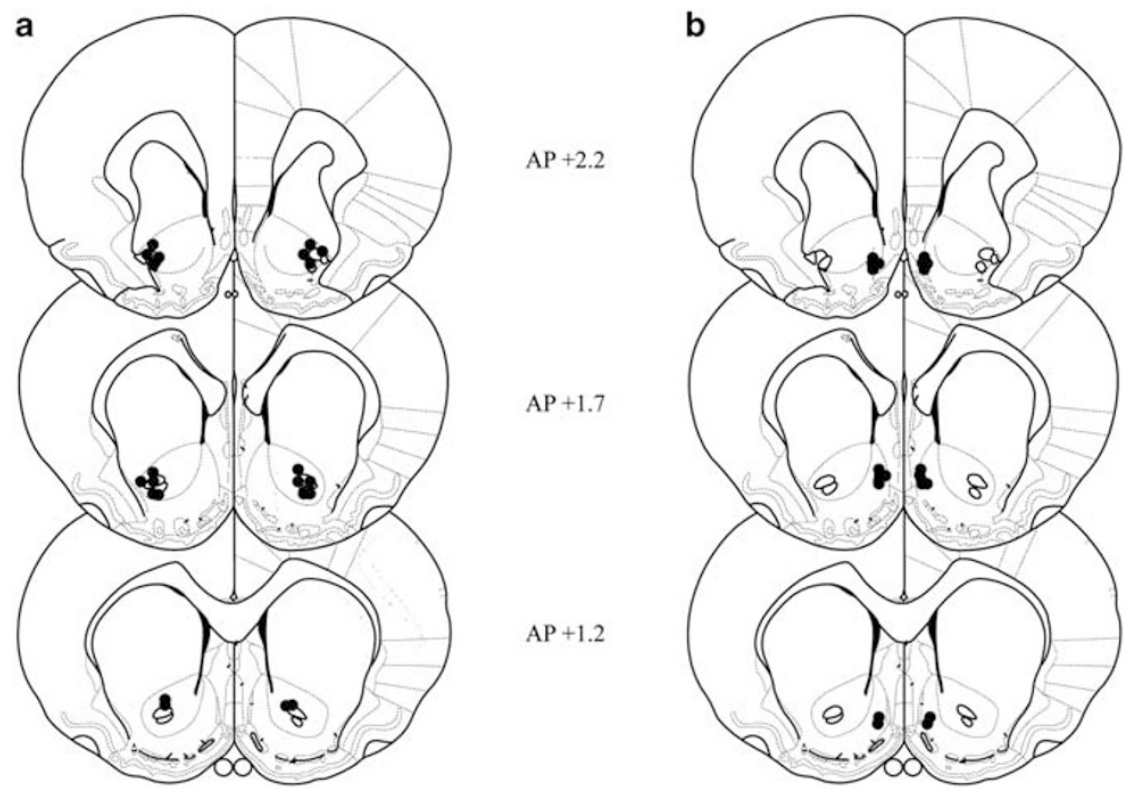

Figure 2 Schematic representations of injector tips in the shell $(n=11)(a)$ and the core $(n=12)(b)$ of the NAcb. Reconstructed from Paxinos and Watson (1998).

$\mathrm{HI}$

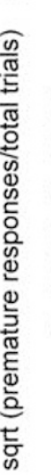

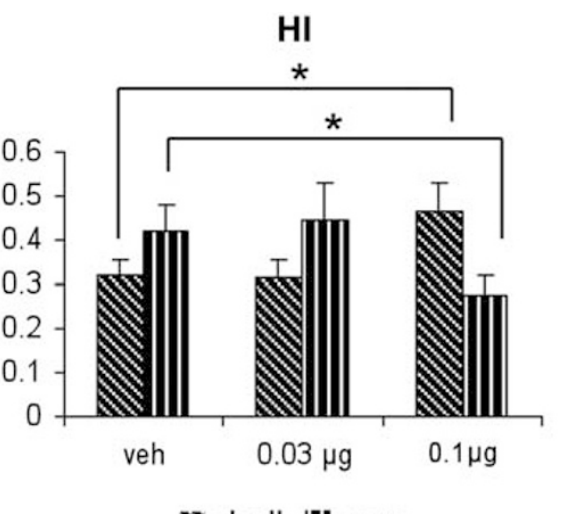

N shell III core

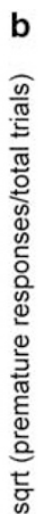

LI

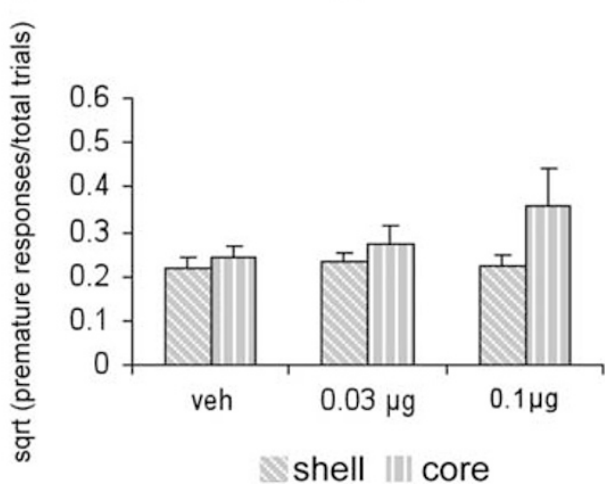

Figure 3 Effects of intra-NAcb shell (diagonal stripes) or core (vertical stripes) microinfusions of nafadotride $(0,0.03$, or $0.1 \mu \mathrm{g}$ per $0.5 \mu \mathrm{l})$ on impulsivity in $\mathrm{HI}$ (a) and $\mathrm{LI}$ (b) rats on the 5-CSRT task. Impulsivity is expressed as square root of premature responses (premature responses/total trials). For the shell experiment, $n=6 \mathrm{HI}$ and $n=5 \mathrm{LI}$ rats. For the core experiment, $n=6 \mathrm{HI}$ and $n=5 \mathrm{LI}$. Doses are expressed in $\mu \mathrm{g} / 0.5 \mu \mathrm{l}$. Each bar represents the mean \pm SEM. $* p \leqslant 0.05$.

nafadotride had opposite effects on the level of premature responses depending on the Nacb subregion into which it was infused (group $\times$ NAcb subregion interaction: $\mathrm{F}(2,20)=7.4125, p \leqslant 0.01$, Figure 3a). Post-hoc analysis showed that impulsivity was significantly increased in $\mathrm{HI}$ rats when nafadotride was infused into the NAcbS at the highest dose tested $(0.1 \mu \mathrm{g}$ vs veh: $p \leqslant 0.05, n=6)$. By contrast, microinfusions of nafadotride into the NAcbC significantly decreased impulsivity in $\mathrm{HI}$ animals at the highest dose tested $(0.1 \mu \mathrm{g} v s$ veh: $p \leqslant 0.05, n=6)$. In LI animals, microinfusions of nafadotride into either the NAcbS $(n=5)$ or the NAcbC $(n=5)$ had no significant effect on premature responding (Figure $3 \mathrm{~b}$ ).

The double dissociation of the effects of microinfusions of nafadotride on impulsivity depending on both the Nacb subregion and the group of animals (HI or LI) tested was further confirmed by three-way ANOVA (group $\times$ drug $\times$ Nacb subregion interaction: $\mathrm{F}(2,36)=7.227, p \leqslant 0.01$; group: $\mathrm{F}(1,18)=9.790, p \leqslant 0.01)$. There were no significant effects of intra-NAcbS and intra-NacbC nafadotride on choice accuracy, omission, perseveration, correct response latencies and magazine latencies (see Supplementary Table 1).

\section{Intra-NAcb Aripiprazole Infusions}

The effects of intra-NAcb infusions of aripiprazole on impulsive responding and other behavioral measures on the 5-CSRT task are shown in Figure 4 and Supplementary Table 2 (see Supplementary online material). Microinfusions of aripiprazole into either the NAcbS or the NAcbC 

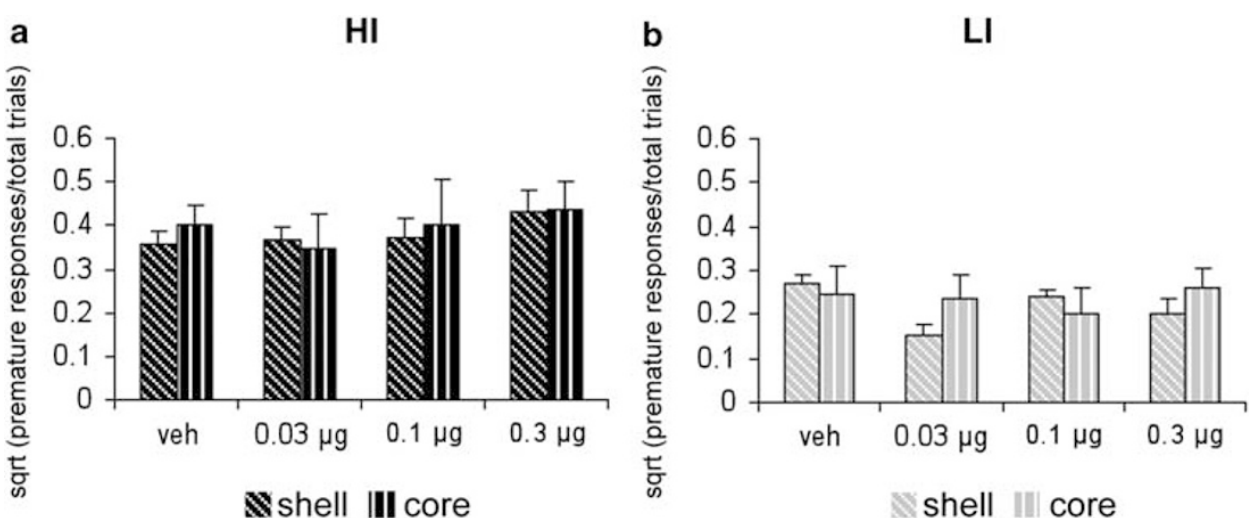

Figure 4 Effects of intra-NAcb shell (diagonal stripes) or core (vertical stripes) microinfusions of aripiprazole $(0,0.03,0.1$, or $0.3 \mu \mathrm{g}$ per $0.5 \mu \mathrm{l})$ on impulsivity in $\mathrm{HI}$ (a) and LI (b) rats on the 5-CSRT task. Impulsivity is expressed as square root of premature responses (premature responses/total trials). For the shell experiment, $n=6 \mathrm{HI}$ and $n=5 \mathrm{LI}$ rats. For the core experiment, $n=6 \mathrm{HI}$ and $n=6 \mathrm{LI}$. Doses are expressed in $\mu \mathrm{g} / 0.5 \mu \mathrm{l}$. Each bar represents the mean \pm SEM.

did not significantly affect impulsive responding in either HI (NAcbS: $n=6$; NAcbC: $n=6$ ) (Figure 4a) or LI (NAcbS: $n=5$; NAcbC: $n=6$ ) rats (Figure $4 \mathrm{~b}$ ).

No significant effects of intra-NAcbS and intra-NacbC aripiprazole microinfusions were observed on choice accuracy, omission, perseveration, correct response latencies, and magazine latencies in either HI or LI animals (see Supplementary Table 2).

\section{Systemic Nafadotride Administration}

The effects of systemic nafadotride on 5-CSRT task performance are shown in Figure 5. Nafadotride significantly increased the number of omissions (drug: $\mathrm{F}(2,26)=$ $10.123, p \leqslant 0.001$, Figure $5 \mathrm{~d})$, in both HI $(n=7)$ and LI animals $(n=8)$ (group $\times$ drug: $\mathrm{F}(2,26)=0.830$, NS). Posthoc analysis showed that this effect was attributable to the highest dose tested ( $3 \mathrm{mg} / \mathrm{kg} v s$ veh: $p \leqslant 0.0001)$. Nafadotride also significantly increased correct response latencies $(\mathrm{F}(2,26)=12.101, p \leqslant 0.001$, Figure $5 \mathrm{e})$ in both $\mathrm{HI}$ and LI rats (group $\times$ drug: $F(2,26)=0.198$, NS). Correct response latencies were significantly increased by nafadotride injections at the highest dose tested ( $3 \mathrm{mg} / \mathrm{kg} v s$ veh: $p \leqslant 0.0001)$. Systemic administration of nafadotride had no effect on impulsive responding, perseveration, attentional accuracy, and magazine latencies (Figures $5 \mathrm{a}-\mathrm{c}$ and $\mathrm{f}$ ).

\section{Systemic Aripiprazole Administration}

The effects of systemic aripiprazole on 5-CSRT task performance are shown in Figure 6.

Aripiprazole significantly decreased impulsivity in both HI $(n=7)$ and LI rats $(n=8)$ (drug: $\mathrm{F}(2,26)=8.200$, $p \leqslant 0.01$; group: $\mathrm{F}(1,13)=9.989, \quad p \leqslant 0.01 ;$ group $\times$ drug: $\mathrm{F}(2,26)=2.495$, NS; Figure 6a). Post-hoc analyses showed that this effect was significant at both doses tested $(1 \mathrm{mg} / \mathrm{kg}$ vs veh: $p \leqslant 0.05 ; 3 \mathrm{mg} / \mathrm{kg}$ vs veh: $p \leqslant 0.01$ ). Systemic aripiprazole also significantly reduced perseverative responding (drug: $\mathrm{F}(2,26)=4.494, p \leqslant 0.05$; group $\times$ drug: $\mathrm{F}(2,26)=2.987$, NS; Figure 6b). Post-hoc analyses revealed that perseverative responding was significantly decreased at both doses tested ( $1 \mathrm{mg} / \mathrm{kg}$ vs veh: $p \leqslant 0.05 ; 3 \mathrm{mg} / \mathrm{kg} v s$ veh: $p \leqslant 0.05)$. In addition, aripiprazole significantly increased omissions (drug: $\mathrm{F}(2,26)=21.373, p \leqslant 0.0001$; group $\times$ drug: $\mathrm{F}(2,26)=0.471$, NS; Figure $6 \mathrm{~d})$, at both doses tested $(1 \mathrm{mg} /$ $\mathrm{kg} v s$ veh: $p \leqslant 0.01 ; 3 \mathrm{mg} / \mathrm{kg} v s$ veh: $p \leqslant 0.001)$. Aripiprazole also increased correct response latencies (drug: $\mathrm{F}(2,20)=$ $4.170, p \leqslant 0.05$; group $\times$ drug: $\mathrm{F}(2,20)=1.250$, NS; Figure $6 \mathrm{e})$, an effect attributable to the highest dose $(p \leqslant 0.05)$. Systemic administration of aripiprazole had no significant effect on attentional choice accuracy (Figure 6c) and magazine latencies (Figure 6f).

\section{DISCUSSION}

This results provide new insights into the neurobiological basis of impulsivity. Nafadotride, a DA D2/3 receptor antagonist, exerted an impulsivity state-dependent, dissociable effect in the NAcbS and NAcbC, increasing the level of impulsivity when infused into the NAcbS, but decreasing it when infused into the NAcbC, selectively in HI animals. Systemically administered nafadotride had no effect on impulsive behavior but increased omission levels and correct response latencies. By contrast, aripiprazole, a DA D2/3 receptor partial agonist, had no effect on impulsive behavior when infused into either the NAcbS or the NAcbC, but decreased impulsive and perseverative behavior, whereas increasing errors of omission and lengthening correct response latencies, when administered systemically.

The NAcb has been widely associated with impulsive behavior in humans and rodents (Cardinal et al, 2001; Aron et al, 2007; Pattij and Vanderschuren, 2008). We have reported that spontaneously high impulsive rats on the 5-CSRT task exhibit a decrease in DA D2/3 receptor availability in the ventral striatum, including the NAcb (Dalley et al, 2007). Dopaminergic function has been broadly implicated in disorders of impulse control mainly on the basis of the evidence that psychostimulants are effective in ADHD (Solanto, 2002; Winstanley et al, 2006). In this study, systemic administration of DA D2/3 agents either had no effect, or nonselectively affected impulsivity, whereas increasing omissions and lengthening correct latencies, suggesting a rather general effect on locomotor 
a

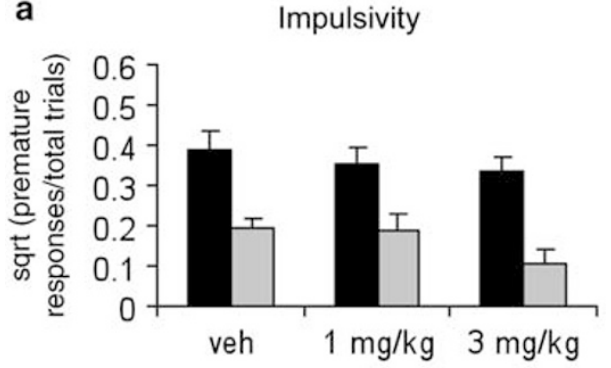

C

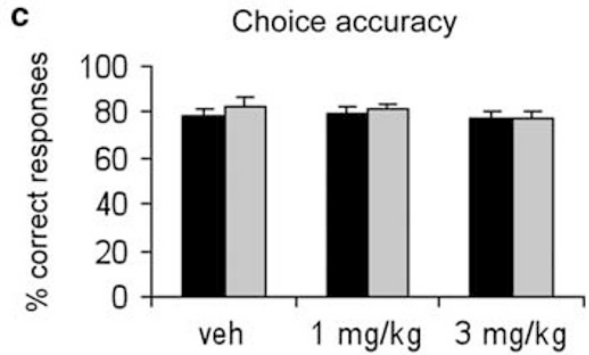

e

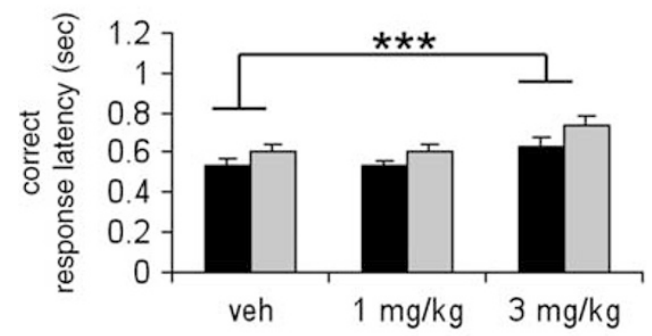

b

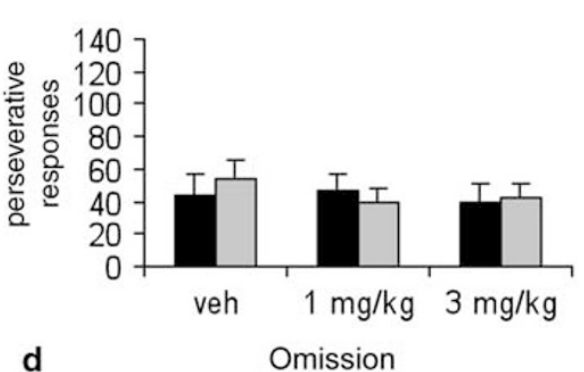

d

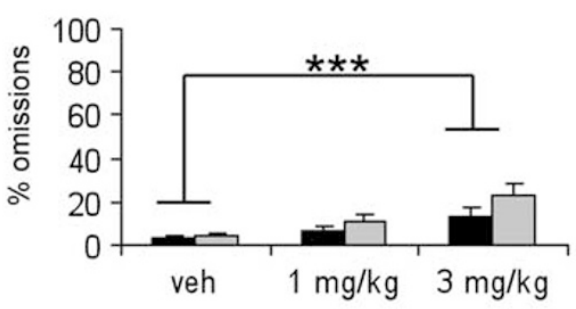

f Magazine latency

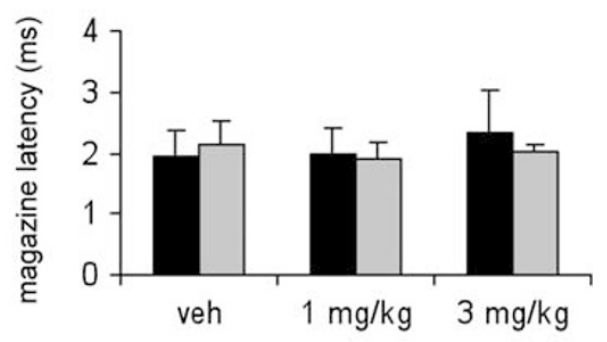

$\mathrm{HI}$

Figure 5 Effects of systemic nafadotride administration on 5-CSRT task performance in HI (black bars, $n=7$ ) and LI rats (gray bars, $n=8$ ). Doses are expressed in $\mathrm{mg} / \mathrm{kg}$. Each bar represents the mean \pm SEM. (a) Impulsivity expressed as square root of premature responses (premature responses/total trials). (b) Perseveration expressed as a number of perseverative nose pokes. (c) Choice accuracy expressed as a percentage of correct responses. (d) Omission expressed as a percentage of omissions. (e) Correct response latency expressed in sec. ( $f$ ) Magazine latency expressed in seconds. **** $p \leqslant 0.001$.

or motivational functions. However, we provide functional evidence that trait-like impulsivity is nonetheless dependent on intra-NAcb DA neurotransmission involving DA D2/3 receptors. As an increasing or decreasing DA neurotransmission enhances or reduces, respectively, impulsivity on the 5-CSRT task (Cole and Robbins, 1989; Pattij and Vanderschuren, 2008), it could be hypothesized that HI rats show increased DA activity as compared with LI animals, as a consequence of too few DA D2/3 receptors in the NAcb (Dalley et al, 2007) functioning as autoreceptors (Viggiano et al, 2003). Indeed, impulsivity on the 5-CSRT task has been associated in vitro with high and low DA release in the NAcbS and NAcbC, respectively (Diergaarde et al, 2008). Accordingly, these results support a subregiondependent dopaminergic basis for inter-individual differences in impulsivity, which may depend on opponent dopaminergic modulation of the NAcb core and shell subregions.

In HI animals, nafadotride decreased impulsivity when infused into the NAcbC. This result is consistent with recent studies showing that intra-NAcbC infusions of D2-like receptor antagonists decrease impulsivity when high levels of this behavior are induced, either by PFC lesions (Pezze et al, 2009) or by amphetamine (Pattij et al, 2007). NAcb D2-like DA receptors have been suggested to regulate behavioral control via cortical and limbic influences possibly through a gating mechanism (Floresco, 2007). Within the NAcb, DA can either enhance or decrease glutamate-induced activity of medium spiny neurons, by actions at D2-like receptors (Yang and Mogenson, 1986; Goto and Grace, 2005). Thus, decreased stimulation of NAcb D2/3 receptors by tonic DA release has been shown to facilitate PFC inputs, and unilateral inactivation of the PFC combined with NAcb D2/3 receptor stimulation decreases inhibitory control during goal-directed behavior (Goto and Grace, 2005). Hence, in this study, blockade of NAcbC DA D2/3 receptors in HI rats may decrease impulsive responding through a facilitation of PFC glutamatergic inputs, thereby increasing PFC control over behavior. This result suggests that, in $\mathrm{HI}$ individuals, intra-NAcbC D2/3mediated DA neurotransmission that negatively modulates PFC glutamatergic inputs would be in a constitutively hyperactive state.

By contrast, intra-NAcbS nafadotride exacerbated impulsive responding in $\mathrm{HI}$ animals, suggesting that the impulsive trait is associated with constitutively hypoactive 

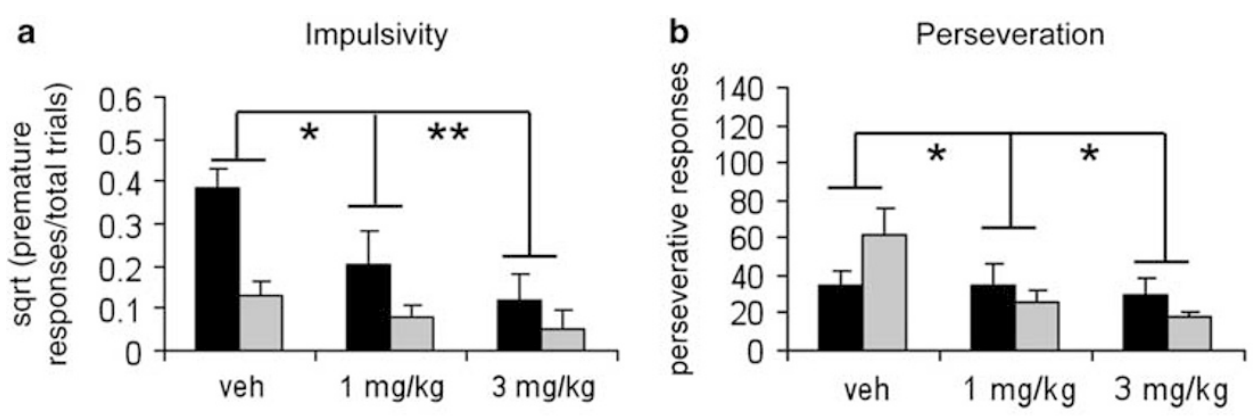

C

Choice accuracy

d

Omission
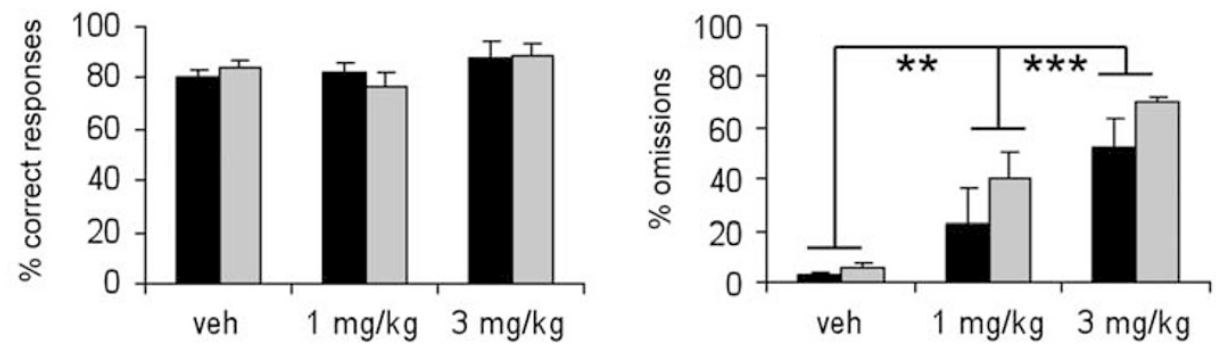

e

Correct response latency

f

Magazine latency
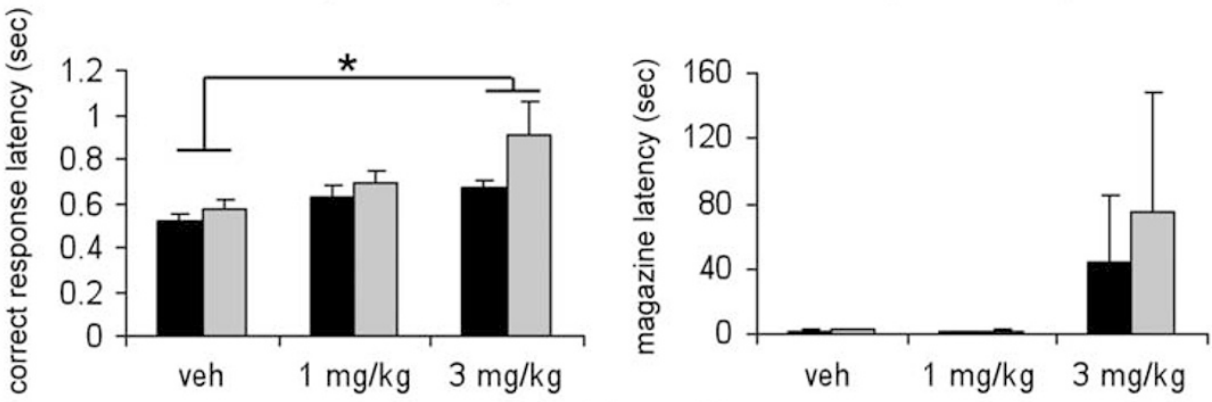

$\mathrm{HI}$

Figure 6 Effects of systemic aripiprazole administration on 5-CSRT task performance in HI (black bars, $n=7$ ) and LI rats (gray bars, $n=8$ ). Doses are expressed in $\mathrm{mg} / \mathrm{kg}$. Each bar represents the mean \pm SEM. (a) Impulsivity expressed as square root of premature responses (premature responses/total trials). (b) Perseveration expressed as a number of perseverative nose pokes. (c) Choice accuracy expressed as a percentage of correct responses. (d) Omission expressed as a percentage of omissions. (e) Correct response latency expressed in seconds. ( $f$ ) Magazine latency expressed in seconds. * $p \leqslant 0.05$, *** $p \leqslant 0.01$, ***** $p \leqslant 0.00$ I.

D2/3-mediated DA neurotransmission in this subregion. Thus, the proposed D2-like receptor-mediated gating mechanism underlying behavioral output might be less efficient in $\mathrm{HI}$ individuals because D2/3-mediated DA neurotransmission in the NAcbS and NAcbC is dysregulated. The apparent lack of effect of systemic nafadotride on impulsivity might result from these opposing actions in both the NAcbS and NAcbC, and not because an insufficient dose of nafadotride was used (see also Boulougouris et al (2008); St Onge and Floresco (2009)). It is also conceivable that brain regions other than the NAcb mediate in part the effects of the systemically administered drugs, potentially through opponent interactions between the PFC and striatum. For example, previous research has strongly implicated the anterior cingulate cortex (Muir et al, 1996), infralimbic cortex (Chudasama et al, 2003), and dorsomedial striatum (Rogers et al, 2001) in the regulation of impulsive behavior.

Previously, it has been shown that intra-NAcbC infusions of the DA D2/3 receptor antagonists sulpiride (Pezze et al,
2009) and eticlopride (Pattij et al, 2007) result in increased omissions and correct response latencies on the 5-CSRT task without affecting impulsive behavior. By contrast, in this study, intra-NAcb infusions of nafadotride generally only affected impulsive responding. As sulpiride and eticlopride are both more selective for DA D2 than DA D3 receptors (Vallone et al, 2000; Levant, 1997), and nafadotride is more selective for DA D3 than DA D2 receptors (Sautel et al, 1995), attentional performance and impulsivity may be differentially modulated by DA D2 and DA D3 receptors, respectively. Consistent with this notion, nafadotride increased omissions and response latencies at doses that would be expected to block DA D2 receptors (Levant and Vansell, 1997).

In this study, intra-NAcbS or NacbC infusions, as well as systemic injections of the DA D2/3 partial agonist aripiprazole, did not modify levels of impulsivity in $\mathrm{HI}$ and LI rats. Aripiprazole is a partial DA receptor agonist with high affinity for both DA D2 and D3 receptors (deLeon et al, 2004). On the basis of the hypothesis that HI and LI 
rats may show hyper- and hypo-DA activity, respectively (Pattij and Vanderschuren, 2008), we had postulated that aripiprazole may have different effects on impulsive behavior in HI and LI rats. In fact, several studies have shown that aripiprazole can have either agonist or antagonist properties at DA D2/3 receptors depending on the level of DA activity (Deleon $e t$ al, 2004). The absence of an effect of aripiprazole on impulsivity in this study might suggest that inter-individual differences in impulsivity on the 5-CSRT task are not related to major differences in DA release, consistent with evidence that HI rats do not show higher striatal DA release than non-impulsive rats (Dalley et al, 2007). The lower number of DA D2/3 receptors in the ventral striatum of $\mathrm{HI}$ rats would hence not seem to be associated with an impairment in presynaptic function, which would directly affect DA tone (Benoit-Marand et al, 2001), but rather to a change in postsynaptic activity. However, previous research has shown that electrically evoked DA release is increased and decreased in the NAcbS and NAcbC, respectively, in HI compared with LI rats (Diergaarde et al, 2008). Therefore, the absence of an effect of aripiprazole on impulsive action might also be due to a concomitant action on pre- and postsynaptic DA D2/3 receptors (Deleon et al, 2004), in contrast to nafadotride, which seems preferentially to block postsynaptic receptors at low doses (Griffon et al, 1995).

These data revealing dissociable roles of DA D2/3 receptors in the NAcbS and NAcbC in impulsive behavior are compatible with previous evidence showing contrasting effects on impulsivity of NAcb shell $v s$ core deep brain stimulation on a reaction-time task, with impulsivity being decreased by NAcbC, but increased by NAcbS stimulation (Sesia et al, 2008). In addition, NAcbC lesions were shown to potentiate, whereas NAcbS lesions were found to attenuate, amphetamine-induced increases in impulsive behavior on a forced choice task (Murphy et al, 2008). Thus, interactions between NAcbS- and NAcbC-dependent mechanisms likely mediate the expression of high impulsivity on the 5-CSRT task. The precise direction of this interaction is unknown but may be relevant to the hierarchical or cascading anatomical arrangement of the ventral midbrain DA system previously described in primates (Haber et al, 2000) and rats (Ikemoto, 2007). Thus, the NAcbS projects to the ventral tegmental area (VTA) that reciprocally projects to the NAcbS, but also to the NAcbC. The NAcbC influences VTA and substantia nigra neurons in turn, and thereby modulates more dorsal structures of the striatum to control behavioral output. Hence, impaired DA D2/3-mediated neurotransmission within the NAcbS might affect the entire DA cascading circuitry, eventually altering NAcbC activity and consequently behavioral output. Such an influence of the NAcbS over NAcbC functioning in the control of behavior has already been implicated in the context of latent inhibition (Weiner et al, 1999) and neural plasticity (Mameli et al, 2009).

Trait-like impulsivity on the 5-CSRT task has recently been identified as a vulnerability marker for cocaine (Dalley et al, 2007; Belin et al, 2008; Economidou et al, 2009) and nicotine (Diergaarde et al, 2008) addiction. A role of the NAcbS has been identified in the reinforcing and stimulant action of cocaine, whereas the NAcbC has been shown to be involved in the acquisition of cocaine-seeking behavior (Ito et al, 2004). Moreover, the circuitry connecting the NAcbC and the dorsal striatum has been shown to mediate the establishment of cocaine-seeking habits (Belin and Everitt, 2008). As striatal DA D2/3 receptors have also been linked to drug seeking (Pilla et al, 1999; Nader et al, 2006; Volkow et al, 2009), a putative dysregulation of DA neurotransmission involving DA D2/3 receptors in the NAcbS and the $\mathrm{NAcbC}$ of HI rats might therefore also account for their propensity to stimulant drug addiction.

\section{ACKNOWLEDGEMENTS}

This study was funded by the Wellcome Trust (076274/2/04/2), MRC (G0600196, G0401068), IMAGEN under the European Communities Sixth Framework Programme (LSHM-CT-2007037286), and the National Institute on Drug Abuse (Intramural Research Program). MB was supported by a 'Fondation pour la Recherche Médicale' fellowship. The authors thank Alan G Lyon for technical assistance.

\section{DISCLOSURE}

TWR discloses consultancy for Cambridge Cognition, Pfizer, E Lilly Inc., Wyeth, GlaxoSmithKline, and Roche and holds share options in Cambridge Cognition and Allon Therapeutics. MB, DB, RM, DT, AC, VB, BC, AN, BE, and JD have no disclosures.

\section{REFERENCES}

Aron AR, Durston S, Eagle DM, Logan GD, Stinear CM, Stuphorn $\mathrm{V}$ (2007). Converging evidence for a fronto-basal-ganglia network for inhibitory control of action and cognition. J Neurosci 27: 11860-11864.

Bari A, Dalley JW, Robbins TW (2008). The application of the 5 -choice serial reaction time task for the assessment of visual attentional processes and impulse control in rats. Nat Protoc 3: 759-767.

Barik A, de Beaurepaire R (2005). Dopamine D3 modulation of locomotor activity and sleep in the nucleus accumbens and in lobules 9 and 10 of the cerebellum in the rat. Prog Neuropsychopharmacol Biol Psychiatry 29: 718-726.

Belin D, Everitt BJ (2008). Cocaine seeking habits depend upon dopamine-dependent serial connectivity linking the ventral with the dorsal striatum. Neuron 57: 432-441.

Belin D, Mar AC, Dalley JW, Robbins TW, Everitt BJ (2008). High impulsivity predicts the switch to compulsive cocaine-taking. Science 320: 1352-1355.

Benoit-Marand M, Borrelli E, Gonon F (2001). Inhibition of dopamine release via presynaptic D2 receptors: time course and functional characteristics in vivo. J Neurosci 21: 9134-9141.

Boulougouris V, Castañé A, Robbins TW (2008). Dopamine D2/D3 receptor agonist quinpirole impairs spatial reversal learning in rats: investigation of $\mathrm{D} 3$ receptor involvement in persistent behavior. Psychopharmacology (Berl) 202: 611-620.

Brewer JA, Potenza MN (2008). The neurobiology and genetics of impulse control disorders: relationships to drug addictions. Biochem Pharmacol 75: 63-75.

Cardinal RN, Aitken MRF (2001). Whisker, version 3.0, computer software. http://www.whiskercontrol.com.

Cardinal RN, Pennicott DR, Sugathapala CL, Robbins TW, Everitt BJ (2001). Impulsive choice induced in rats by lesions of the nucleus accumbens core. Science 292: 2499-2501. 
Chudasama Y, Passetti F, Rhodes SE, Lopian D, Desai A, Robbins TW (2003). Dissociable aspects of performance on the 5-choice serial reaction time task following lesions of the dorsal anterior cingulate, infralimbic and orbitofrontal cortex in the rat: differential effects on selectivity, impulsivity and compulsivity. Behav Brain Res 146: 105-119.

Cole BJ, Robbins TW (1989). Effects of 6-hydroxydopamine lesions of the nucleus accumbens septi on performance of a 5-choice serial reaction time task in rats: implications for theories of selective attention and arousal. Behav Brain Res 33: 165-179.

Dalley JW, Fryer TD, Brichard L, Robinson ES, Theobald DE, Lääne $\mathrm{K}$ et al (2007). Nucleus accumbens D2/3 receptors predict trait impulsivity and cocaine reinforcement. Science 315: $1267-1270$.

Dalley JW, Mar AC, Economidou D, Robbins TW (2008). Neurobehavioral mechanisms of impulsivity: fronto-striatal systems and functional neurochemistry. Pharmacol Biochem Behav 90: 250-260.

DeLeon A, Patel NC, Crismon ML (2004). Aripiprazole: a comprehensive review of its pharmacology, clinical efficacy, and tolerability. Clin Ther 26: 649-666.

Diergaarde L, Pattij T, Poortvliet I, Hogenboom F, de Vries W, Schoffelmeer AN et al (2008). Impulsive choice and impulsive action predict vulnerability to distinct stages of nicotine seeking in rats. Biol Psychiatry 63: 301-308.

Eagle DM, Bari A, Robbins TW (2008). The neuropsychopharmacology of action inhibition: cross-species translation of the stop-signal and go/no-go tasks. Psychopharmacology (Berl) 199: 439-456.

Economidou D, Pelloux Y, Robbins TW, Dalley JW, Everitt BJ (2009). High impulsivity predicts relapse to cocaine-seeking after punishment-induced abstinence. Biol Psychiatry 65: 851-856.

Floresco SB (2007). Dopaminergic modulation of limbic-striatal interplay. J Psychiatry Neurosci 32: 400-411.

Griffon N, Sokoloff P, Diaz J, Lévesque D, Sautel F, Schwartz JC et al (1995). The dopamine D3 receptor and schizophrenia: pharmacological, anatomical and genetic approaches. Eur Neuropsychopharmacol 5: 3-9.

Goto Y, Grace AA (2005). Dopaminergic modulation of limbic and cortical drive of nucleus accumbens in goal-directed behavior. Nat Neurosci 8: 805-812.

Groenewegen HJ, Wright CI, Beijer AV, Voorn P (1999). Convergence and segregation of ventral striatal inputs and outputs. Ann N Y Acad Sci 877: 49-63.

Haber SN, Fudge JL, McFarland NR (2000). Striatonigrostriatal pathways in primates form an ascending spiral from the shell to the dorsolateral striatum. J Neurosci 20: 2369-2382.

Ikemoto S (2007). Dopamine reward circuitry: two projection systems from the ventral midbrain to the nucleus accumbensolfactory tubercle complex. Brain Res Rev 56: 27-78.

Ito R, Robbins TW, Everitt BJ (2004). Differential control over cocaine-seeking behavior by nucleus accumbens core and shell. Nat Neurosci 7: 389-397.

Levant B (1997). The D3 dopamine receptor: neurobiology and potential clinical relevance. Pharmacol Rev 49: 231-252.

Levant B, Vansell NR (1997). In vivo occupancy of D2 dopamine receptors by nafadotride. Neuropsychopharmacology 17: 67-71.

Mameli M, Halbout B, Creton C, Engblom D, Parkitna JR, Spanagel $\mathrm{R}$ et al (2009). Cocaine-evoked synaptic plasticity: persistence in the VTA triggers adaptations in the Nac. Nature Neurosci 12: 1036-1041.

Mogenson GJ, Jones DL, Yim CY (1980). From motivation to action: functional interface between the limbic system and the motor system. Prog Neurobiol 14: 69-97.

Muir JL, Everitt BJ, Robbins TW (1996). The cerebral cortex of the rat and visual attentional function: Dissociable effects of mediofrontal, cingulate, anterior dorsolateral, and parietal cortex lesions on a five-choice serial reaction time task. Cerebral Cortex 6: 470-481.

Murphy ER, Robinson ES, Theobald DE, Dalley JW, Robbins TW (2008). Contrasting effects of selective lesions of nucleus accumbens core or shell on inhibitory control and amphetamine-induced impulsive behaviour. Eur $J$ Neurosci 28: 353-363.

Nader MA, Morgan D, Gage HD, Nader SH, Calhoun TL, Buchheimer $\mathrm{N}$ et al (2006). PET imaging of dopamine D2 receptors during chronic cocaine self-administration in monkeys. Nat Neurosci 9: 1050-1056.

Nordquist RE, Risterucci C, Moreau JL, von Kienlin M, Künnecke B, Maco M et al (2008). Effects of aripiprazole/ OPC-14597 on motor activity, pharmacological models of psychosis, and brain activity in rats. Neuropharmacology 54: 405-416.

Pattij T, Janssen MC, Vanderschuren LJ, Schoffelmeer AN, van Gaalen MM (2007). Involvement of dopamine D1 and D2 receptors in the nucleus accumbens core and shell in inhibitory response control. Psychopharmacology (Berl) 191: 587-598.

Pattij T, Vanderschuren LJ (2008). The neuropharmacology of impulsive behaviour. Trends Pharmacol Sci 29: 192-199.

Paxinos G, Watson C (1998). The Rat Brain in Stereotaxic Coordinates. Academic Press: Orlando, FL.

Pezze MA, Dalley JW, Robbins TW (2009). Remediation of attentional dysfunction in rats with lesions of the medial prefrontal cortex by intra-accumbens administration of the dopamine $\mathrm{D}(2 / 3)$ receptor antagonist sulpiride. Psychopharmacology (Berl) 202: 307-313.

Pilla M, Perachon S, Sautel F, Garrido F, Mann A, Wermuth CG et al (1999). Selective inhibition of cocaine-seeking behaviour by a partial dopamine D3 receptor agonist. Nature 400: 371-375.

Robbins TW, Everitt BJ (1996). Neurobehavioural mechanisms of reward and motivation. Curr Opin Neurobiol 6: 228-236.

Robinson ES, Eagle DM, Economidou D, Theobald DE, Mar AC, Murphy ER et al (2009). Behavioural characterisation of high impulsivity on the 5-choice serial reaction time task: specific deficits in 'waiting' vs 'stopping'. Behav Brain Res 196: 310-316.

Rogers RD, Baunez C, Everitt BJ, Robbins TW (2001). Lesions of the medial and lateral striatum in the rat produce differential deficits in attentional performance. Behav Neurosci 115: 799-811.

Sautel F, Griffon N, Sokoloff P, Schwartz JC, Launay C, Simon P et al (1995). Nafadotride, a potent preferential dopamine D3 receptor antagonist, activates locomotion in rodents. J Pharmacol Exp Ther 275: 1239-1246.

Sesia T, Temel Y, Lim LW, Blokland A, Steinbusch HW, VisserVandewalle V (2008). Deep brain stimulation of the nucleus accumbens core and shell: Opposite effects on impulsive action. Exp Neurol 214: 135-139.

Solanto MV (2002). Dopamine dysfunction in AD/HD: integrating clinical and basic neuroscience research. Behav Brain Res 130: 65-71.

St Onge JR, Floresco SB (2009). Dopaminergic modulation of risk-based decision making. Neuropsychopharmacology 34: 681-697.

Vallone D, Picetti R, Borrelli E (2000). Structure and function of dopamine receptors. Neurosci Biobehav Rev 24: $125-132$.

Viggiano D, Ruocco LA, Sadile AG (2003). Dopamine phenotype and behaviour in animal models: in relation to attention deficit hyperactivity disorder. Neurosci Biobehav Rev 27: 623-637. 
Weiner I, Gal G, Feldon J (1999). Disrupted and undisruptable latent inhibition following shell and core lesions. Ann N Y Acad Sci 877: 723-727.

Winstanley CA, Eagle DM, Robbins TW (2006). Behavioral models of impulsivity in relation to ADHD: translation between clinical and preclinical studies. Clin Psychol Rev 26: 379-395.

Volkow ND, Fowler JS, Wang GJ, Baler R, Telang F (2009). Imaging dopamine's role in drug abuse and addiction. Neuropharmacology 56: 3-8.
Yang CR, Mogenson GJ (1986). Dopamine enhances terminal excitability of hippocampal-accumbens neurons via D2 receptor: role of dopamine in presynaptic inhibition. J Neurosci 6: $2470-2478$.

Zahm DS (1999). Functional-anatomical implications of the nucleus accumbens core and shell subterritories. Ann N Y Acad Sci 877: 113-128.

Zahm DS (2000). An integrative neuroanatomical perspective on some subcortical substrates of adaptive responding with emphasis on the nucleus accumbens. Neurosci Biobehav Rev 24: 85-105.

Supplementary Information accompanies the paper on the Neuropsychopharmacology website (http://www.nature.com/npp) 